\title{
Design and Test of a Flow Valve Orifice in a Crane Hoisting System
}

\section{LI, Mingsheng}

College of Engineering and Technology, Southwest University

\section{MITSUOKA, Muneshi}

Laboratory of Agricultural Machinery and Production Systems Design, Division of Bioproduction Environmental Sciences, Department of Agro-environmental Sciences, Faculty of Agriculture, Kyushu University

\section{INOUE, E i j i}

Laboratory of Agricultural Machinery and Production Systems Design, Division of Bioproduction Environmental Sciences, Department of Agro-environmental Sciences, Faculty of Agriculture, Kyushu University

\section{OKAYASU, Takashi}

Laboratory of Agricultural Machinery and Production Systems Design, Division of Bioproduction Environmental Sciences, Department of Agro-environmental Sciences, Faculty of Agriculture, Kyushu University

他

https://doi.org/10.5109/2558905

出版情報 : 九州大学大学院農学研究院紀要. 65 (1)，pp.131-138，2020-02. Faculty of Agriculture， Kyushu University

バージョン :

権利関係 : 


\title{
Design and Test of a Flow Valve Orifice in a Crane Hoisting System
}

\author{
Mingsheng LI ${ }^{1 *}$, Muneshi MITSUOKA ${ }^{2}$, Eiji INOUE ${ }^{2}$, Takashi OKAYASU ${ }^{2}$, \\ Yasumaru HIRAI ${ }^{2}$ and Xiaoxia SONG $^{3}$
}

\author{
Laboratory of Agricultural Machinery and Production Systems Design, Division of Bioproduction \\ Environmental Sciences, Department of Agro-environmental Sciences, Faculty of Agriculture, \\ Kyushu University, Fukuoka 819-0395, Japan \\ (Received October 30, 2019 and accepted November 14, 2019)
}

\begin{abstract}
A combined orifice is designed for the flow valve in a crane hoisting system. The structure and parameters of the combined orifice are calculated and designed according to analysis of the characteristics of the commonly used single orifice and considering the requirements of the crane hoisting system. The equivalent flow area and computational fluid dynamics are adopted in simulating the flow area and pressure loss of the combined orifice. A model of the crane hoisting system is established in AMESim software and the control performance of the combined orifice on the hoisting speed is simulated and analyzed. Simulation results show that the maximum equivalent flow area of the combined orifice is $213 \mathrm{~mm}^{2}$, the pressure loss is $1.28 \mathrm{MPa}$ when the throttle opening is a maximum at the rated flow rate and the maximum hoisting speed is $150 \mathrm{~m} / \mathrm{min}$ for no load and $110 \mathrm{~m} / \mathrm{min}$ for a heavy load. A speed regulation performance test of the crane hoisting system shows that the maximum hoisting speed is $150 \mathrm{~m} / \mathrm{min}$ for no load and $112 \mathrm{~m} / \mathrm{min}$ for a heavy load and the minimum stable speed of hoisting system is less than $1.83 \mathrm{~m} / \mathrm{min}$ under different working conditions.
\end{abstract}

Key words: Crane hoisting system, Combined orifice, Computational fluid dynamics, Speed regulation, Performance test

\section{INTRODUCTION}

The flow valve is a core hydraulic component of a crane. It controls the speed of the hoisting system by controlling the flow into the hydraulic motor. The improvement of flow control accuracy will improve the motion accuracy of the hoisting system. Therefore, the flow control accuracy of the flow control valve will greatly affect the performance of the crane hoisting system.

The flow valve is essentially an orifice valve whereby the flow is regulated by changing the orifice flow area. The orifice section area is determined by the structure of the orifice. The orifice structure therefore has a decisive effect on the flow control performance of the flow control valve.

Researchers have studied the structure of the orifice port in detail in efforts to improve the control accuracy of the flow valve. Orifices can be categorized by their structure, such as U-type, L-type and V-type (Na, C. L, 2011; Ji, H et al., 2003; Ji, H et al., 2010). With a change in orifice width, different orifice structures have different flow section area curves. However, a single orifice structure cannot meet the requirements of complex flow changes. Researchers have therefore combined orifices and obtained abundant flow curves (Zhou, H et al., 2008;

College of Engineering and Technology, Southwest University, China

${ }^{2}$ Laboratory of Agricultural Machinery and Production Systems Design, Division of Bioproduction Environmental Sciences, Department of Agro-environmental Sciences, Faculty of Agriculture, Kyushu University, Japan

School of Foreign Languages, Chongqing College of Humanities, Science \&Technology, China

* Corresponding author (E-mail: limingshengSWU@vip.163. com)
Wu, X. M et al., 2010).

The hoisting system is used by a crane to lift and lower heavy objects. The hoisting system must run smoothly to ensure the safety of crane work and should also be able to operate at a lower speed that ensures the accuracy of work. At the same time, for better efficiency of crane operation, the hoisting system of the crane must have a higher moving speed when needing to lift and lower heavy objects quickly. The flow valve of the crane hoisting system should therefore have a large flow regulation range and provide a lower and stable flow for the hydraulic motor when the hoisting system works at low speed. These requirements can be achieved through appropriate orifice design. Researchers have made good progress in verifying the orifice performance and optimizing the orifice design using MATLAB and AMESIM software to model and simulate orifices (Dasgupta, K et al., 2002; Yuan, S.H et al., 2013).

In addition to meeting the basic working requirements, a crane hoisting system should have good energy efficiency to prevent the system from stopping working as a consequence of the overheating of hydraulic oil. Relevant research shows that most of the energy loss of the hoisting system is due to the hydraulic system and that the orifice of the flow valve is the main location of the energy loss. In recent years, researchers have adopted computational fluid dynamics (CFD) to study the energy loss at an orifice (Amirante, R et al., 2007; Li, $\mathrm{Z}$ et al., 2012). Results show that the CFD method can be used to effectively simulate and analyze the oil flow and energy loss at the orifice.

In this study, to improve the efficiency and stability of the crane hoisting system, the flow performances of four types of commonly used single orifices of the flow valve are compared and analyzed. On the basis of the analysis results, a combined orifice is designed to meet 
the needs of a hoisting system. CFD are then used to simulate the oil flow and energy loss at the orifice and AMESim software is used to simulate the orifice flow capacity. Finally, the regulating effect of the combined orifice designed in this study on the hoisting system action is tested on a crane.

\section{MATERIALS AND METHODS}

\section{Analysis of a commonly used single orifice}

The throttle orifice is formed by the body of the flow valve enclosing a spool. There are two types of throttle orifices, full-cycle orifices and non-full-cycle orifices. The commonly used full-cycle orifices are annular and conical, as shown in Figure 1 (a) and (b). These throttles are annular areas formed by body holes around a spool. The commonly used non-full-cycle orifices are U-shaped and V-shaped, as shown in Figure 1 (c) and (d). These orifices are machined on a spool. The flow areas of all orifices vary with the opening width of the orifices. Therefore, before the orifices are designed, it is necessary to study the variation in the orifice flow area with the opening width of the orifice.

The flow direction of hydraulic oil changes as oil passes through the throttle orifice. In Figure 2, the flow area is A1 when oil enters the spool throttle orifice along the direction perpendicular to the axis of the spool. After entering the throttle orifice, the oil flows in a direction parallel to the axis of the valve spool and the flow area is A2. Relevant studies have shown that the equivalent orifice flow area is approximately equal to the smaller of A1 and A2, and the smaller of A1 and A2 is thus taken as the equivalent orifice flow area in the present study.

Using the above calculation method, the equivalent flow areas of the four common orifices in Figure 1 are calculated and the curves of the equivalent flow areas varying with the opening width of the orifices are obtained, as shown in Figure 3. The figure shows that the equivalent flow area increases with the opening

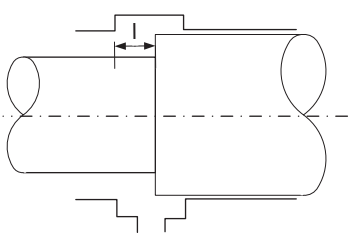

(a)

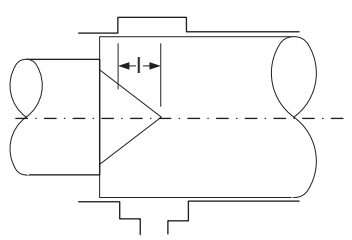

(c)

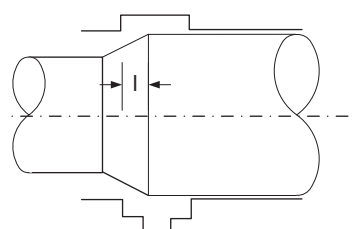

(b)

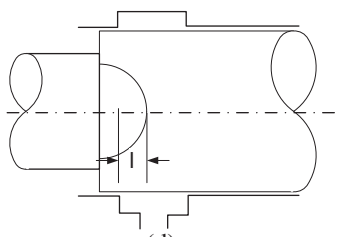

(d) (a) Annular full-cycle orifice (b) Conical full-cycle orifice (c) V-shaped non-full-cycle orifice (d) U-shaped non-full-cycle orifice

Fig. 1. Common types of throttle orifice.

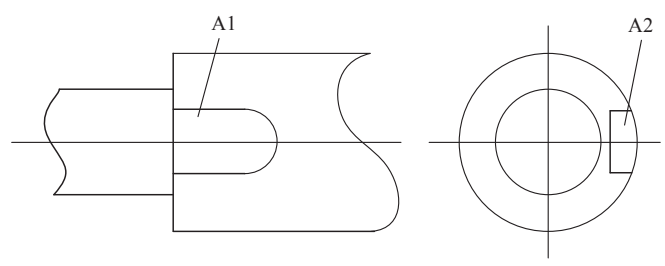

Fig. 2. Throttle orifice flow areas.

width for all orifices. For the same opening width, the equivalent flow area of the annular orifice is largest and that of the V-shaped orifice is smallest. When the opening width of the orifice is relatively short, the flow areas of V-shaped and U-shaped orifices are very small. When the throttle opening is increased, the gains of the flow areas of the annular and U-shaped orifices are larger. The U-shaped orifice has a small flow area that changes stably for short widths of the orifice opening and a large gain in the flow area for long widths of the orifice opening. These characteristics meet the requirements of high stability for a crane hoisting system operating at low speed and high working efficiency for a crane hoisting system operating at high speed. $A_{n}$ U-shaped orifice combination is therefore selected in the present study for the design of the orifice of the flow valve of a crane hoisting system.

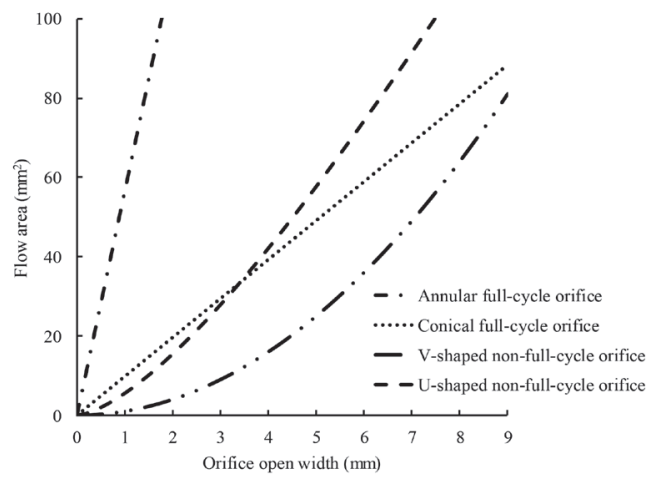

Fig. 3. Curves of the equivalent flow area versus orifice opening width.

\section{Design of a combined orifice for the flow valve of a crane hoisting system}

The maximum flow rate $q$ of the considered crane hoisting hydraulic system is $350 \mathrm{~L} / \mathrm{min}$ and the maximum pressure is $31.5 \mathrm{MPa}$. The pressure loss at the orifice should be less than 1.5 MPa. Research shows that to prevent the unstable flow of hydraulic oil due to a flow rate that is too high, the large diameter $D$ of the valve spool should satisfy the condition

$$
D \geq 11.25 \frac{\sqrt{q}}{\sqrt[4]{\Delta p}}=11.25 \frac{\sqrt{350 / 60000}}{\sqrt[4]{1500000}} \approx 24.5(\mathrm{~mm}) .
$$

Therefore, $D$ is taken as $25 \mathrm{~mm}$.

To ensure the strength of the spool, the small diameter $d$ of the spool should satisfy the condition

$$
d \geq 0.5 D=12.5(\mathrm{~mm}) .
$$


Therefore, $d$ is taken as $13 \mathrm{~mm}$.

Figure 4 presents the design of combined orifices of the flow valve in the crane hoisting system, using Ushaped non-full-cycle orifices. Pairs of two types of combined orifices are designed on the circumference of the spool. The first type of combined orifice comprises U1, U2 and U3 orifices. The second type of combined orifice comprises U4 and U5 orifices. The orifices of each combination intersect each other and are distributed evenly on the circumference of the spool to prevent the spool from sticking.

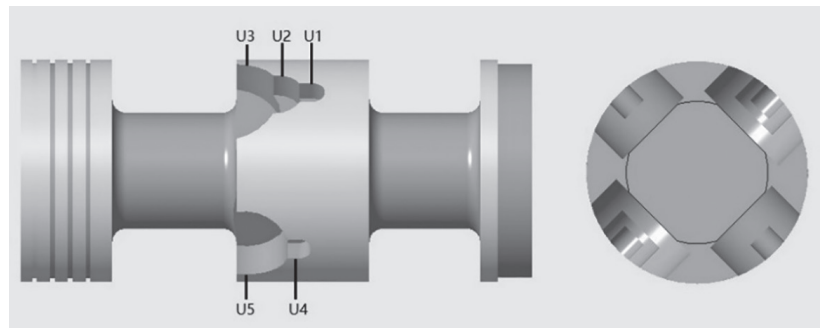

Fig. 4. Combined orifices of the flow valve in the crane hoisting system.

The structural parameters of the above two types of combined orifice are given in Table 1 . The maximum opening width of the $\mathrm{U} 1+\mathrm{U} 2+\mathrm{U} 3$ combined orifice is 10 $\mathrm{mm}$ while that of the U4+U5 combined orifice is $8.5 \mathrm{~mm}$.

The opening width $L$ of the combined orifices varies with the movement of the spool, as shown in Figure 5.

Curves of the equivalent flow area of the combined orifices versus the opening width are shown in Figure 6. It is seen that the maximum opening width of the combined orifices is $10 \mathrm{~mm}$. The total flow area is low (increasing from 0 to $60 \mathrm{~mm}^{2}$ ) for opening widths of $0-5.2 \mathrm{~mm}$ and increases rapidly from 60 to $213 \mathrm{~mm}^{2}$ for opening widths of $5.2-10 \mathrm{~mm}$.

Table 1. Structural parameters of combined throttles

\begin{tabular}{cl}
\hline Combined throttles & \multicolumn{1}{c}{ Structural parameters } \\
\hline & U1: radius $R_{1}=1.5 \mathrm{~mm}$, length $L_{1}=2.5 \mathrm{~mm}$, \\
& depth $D_{1}=2.5 \mathrm{~mm}$ \\
& U2: radius $R_{2}=3.0 \mathrm{~mm}$, length $L_{2}=2.5 \mathrm{~mm}$, \\
& depth $D_{2}=3.5 \mathrm{~mm}$ \\
& U3: radius $R_{3}=6.0 \mathrm{~mm}$, length $L_{3}=5.0 \mathrm{~mm}$, \\
& depth $D_{3}=5.5 \mathrm{~mm}$ \\
& U4: radius $R_{4}=1.5 \mathrm{~mm}$, length $L_{4}=2.5 \mathrm{~mm}$, \\
& depth $D_{4}=2.5 \mathrm{~mm}$ \\
U5 4 : $\operatorname{radius} R_{5}=5.0 \mathrm{~mm}$, length $L_{5}=6.0 \mathrm{~mm}$, \\
& depth $D_{5}=5.5 \mathrm{~mm}$ \\
\hline
\end{tabular}

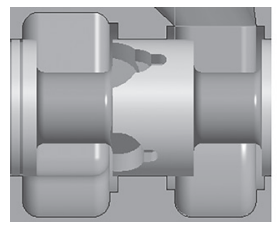

$L=0 \mathrm{~mm}$

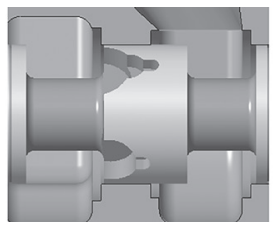

$L=1.5 \mathrm{~mm}$

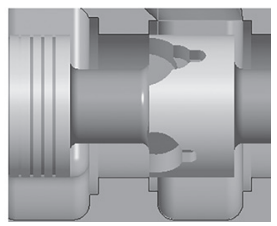

$L=10 \mathrm{~mm}$
Fig. 5. Change in the combined orifice opening width $L$ when the spool moves.

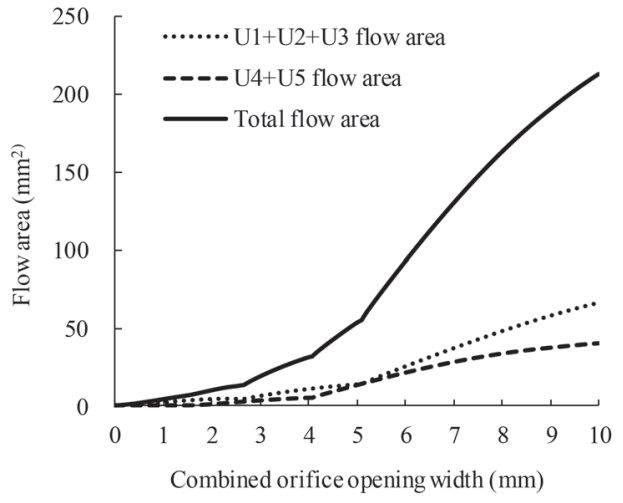

Fig. 6. Equivalent flow area of combination orifices versus the opening width.

\section{Simulation of the flow field of combined orifices}

The structural relationship between the valve body and the spool of the flow valve in the hoisting system of the crane is shown in Figure 7.

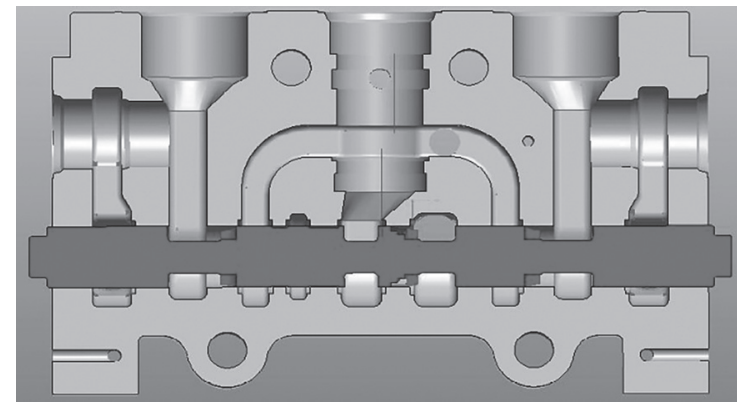

Fig. 7. Profile of the flow valve in the crane hoisting system.

To study the oil flow at the combined orifice, the CFD method is used to analyze the pressure distribution at the combined orifice for different opening widths. First, the flow valve model is simplified to obtain the flow field simulation model of the fluid area surrounded by the valve body and spool. The model is then meshed as shown in Figure 8.

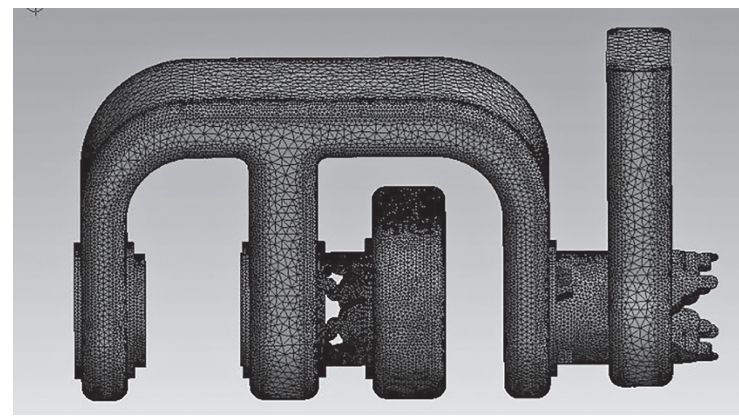

Fig. 8. Mesh generation of the fluid zone model surrounded by the valve body and spool.

Simulation parameters are given in Table 2. 
Table 2. Main parameters of the CFD model

\begin{tabular}{ll}
\hline \multicolumn{1}{c}{ Name } & \multicolumn{1}{c}{ Parameters } \\
\hline Solution Type & Pressure-Based \\
Analysis Type & Steady \\
Fluid model & Realizable k- $\varepsilon$ \\
Fluid materials & $46 \#$ hydraulic oil \\
Inlet hydraulic radius (m) & 0.02254 \\
Outlet hydraulic radius (m) & 0.002636 \\
\hline
\end{tabular}

\section{Simulation of the crane hoisting system perfor- mance}

A simulation model of the crane hoisting system is established using AMESim software as shown in Figure 9 to study the performance of the designed combined orifice of the flow valve in the crane hoisting system. The simulation model includes a hydraulic pump, hydraulic motor, reducer, flow valve and pressure compensation valve. The pressure compensation valve maintains a constant pressure drop at the combined orifice, thereby reducing the effect of the workload on the flow.

Parameters of the crane hoisting system simulation model are given in Table 3.

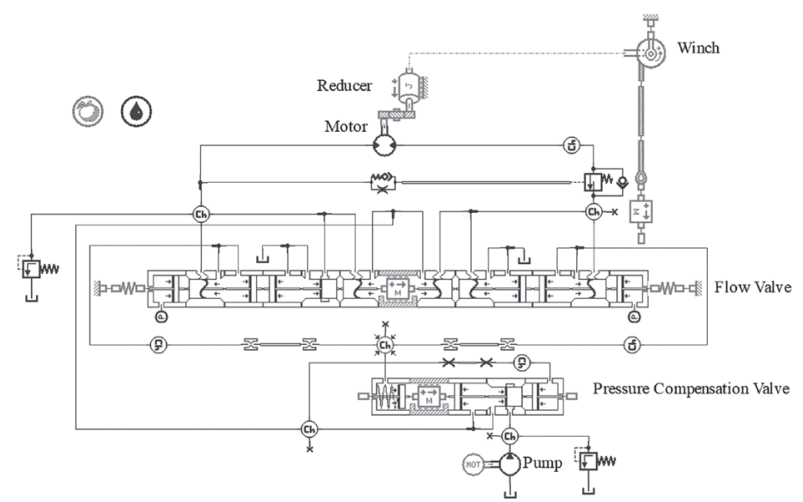

Fig. 9. Simulation model of the crane hoisting system in AMESim software.

Table 3. Parameters of the crane hoisting system simulation model

\begin{tabular}{ll}
\hline \multicolumn{1}{c}{ Parameters } & value \\
\hline Oil density $\left(\mathrm{kg} \cdot \mathrm{m}^{-3}\right)$ & 850 \\
Oil absolute viscosity $(\mathrm{MPa} \cdot \mathrm{s})$ & 20.76 \\
Bulk modulus $(\mathrm{MPa})$ & 1700 \\
Oil temperature $\left({ }^{\circ} \mathrm{C}\right)$ & 40 \\
Pump displacement $(\mathrm{mL} / \mathrm{r})$ & 200 \\
Motor displacement $(\mathrm{mL} / \mathrm{r})$ & 107 \\
Gear ratio & 17 \\
Diameter of winch $(\mathrm{mm})$ & 250
\end{tabular}

\section{Performance test of the crane hoisting system}

The speed regulation performance of the combined orifice on the hoisting system was tested on an XCT55 crane. Part of the measuring point arrangement of the hydraulic system is shown in Figure 10. The composition of the test system is given in Table 4.
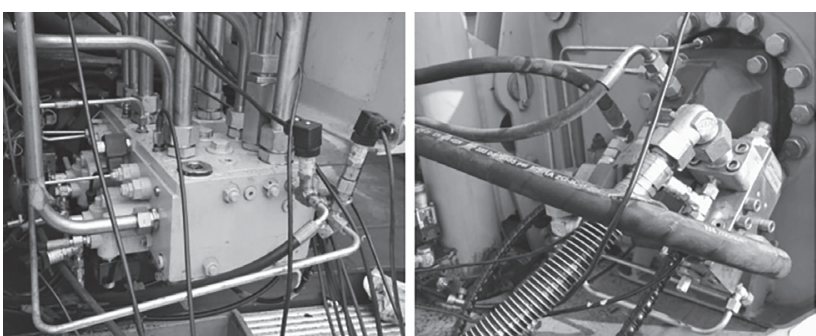

Fig. 10. Measurement point layout of the hydraulic system.

Table 4. Composition of the crane test system

\begin{tabular}{ll}
\hline \multicolumn{1}{c}{ Elements } & \multicolumn{1}{c}{ Parameters } \\
\hline Hydraulic pump & $100 \mathrm{ml} / \mathrm{r}+100 \mathrm{ml} / \mathrm{r}$ \\
Hydraulic motor & $107 \mathrm{ml} / \mathrm{r}$ \\
Pilot circuit oil pressure sensor & $0-10 \mathrm{MPa}$ \\
Main circuit oil pressure sensor & $0-40 \mathrm{MPa}$ \\
Winch speed sensor & $1000 \mathrm{Plus} / \mathrm{R}$ \\
\hline
\end{tabular}

\section{RESULTS AND DISCUSSION}

\section{Simulation results and analysis of the flow field of the combined orifice}

The flow-field simulation scheme of the combined orifice is designed as shown in Table 5.

Table 5. Flow-field simulation scheme of the combined orifice

\begin{tabular}{ccccc}
\hline Simulation & $\begin{array}{c}\text { Opening } \\
\text { width } L \\
(\mathrm{~mm})\end{array}$ & $\begin{array}{c}\text { Inlet velocity } \\
v(\mathrm{~m} / \mathrm{s})\end{array}$ & $\begin{array}{c}\text { Equivalent } \\
\text { flow rate } Q \\
(\mathrm{~L} / \mathrm{min})\end{array}$ & $\begin{array}{c}\text { Outlet pres- } \\
\text { sure } p_{l} \\
(\mathrm{MPa})\end{array}$ \\
\hline 1 & 2 & 0.52 & 10.8 & 28 \\
2 & 4 & 1.3 & 26.6 & 28 \\
3 & 7 & 7 & 150 & 28 \\
4 & 10 & 16 & 350 & 28 \\
\hline
\end{tabular}

Simulation results of the pressure distribution for different orifice opening widths are shown in Figure 11.

Figure 11 shows that the pressure loss of the flow valve mainly relates to the combined orifice. In flow field simulations 1 to 4 , the pressure losses at the orifice are respectively $0.76,0.43,1.19$ and $1.28 \mathrm{MPa}$. In each case, the pressure loss at the orifice is less than $1.5 \mathrm{MPa}$, which meets design requirements.

\section{Simulation results and analysis of the crane hoist- ing system performance}

Table 6 presents the scheme for simulating and analyzing the performance of the hoisting speed control of the crane hoisting system at different engine speeds and different workloads, according to the actual working conditions of the crane.

The simulation results of the hoisting speed of crane are shown in Figure 12. 


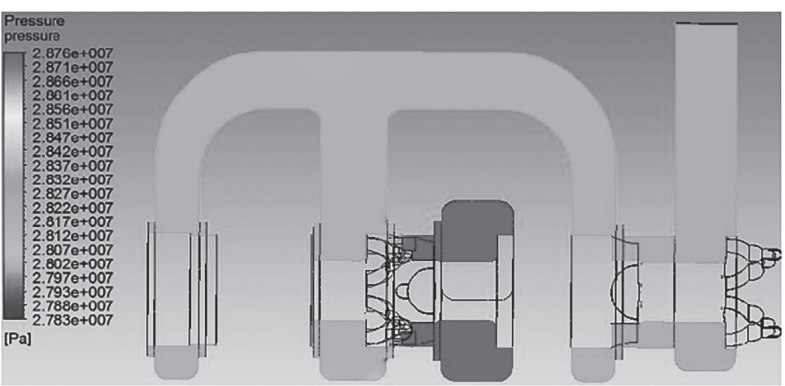

Simulation $1: L=2 \mathrm{~mm}, v=0.52 \mathrm{~m} / \mathrm{s}, Q=10.8 \mathrm{~L} / \mathrm{min}$

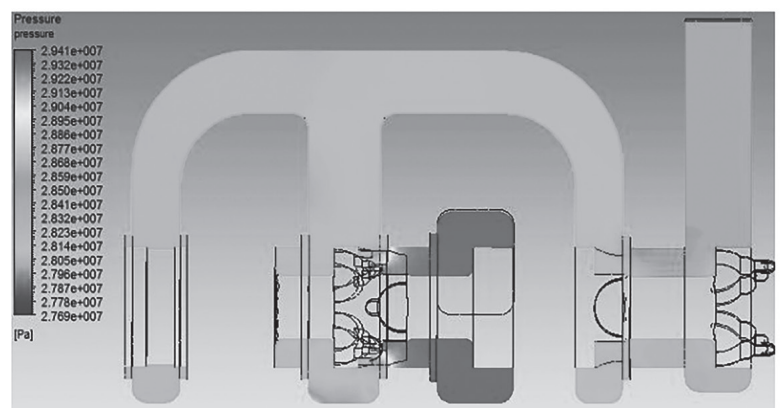

Simulation $3: L=7 \mathrm{~mm}, v=7 \mathrm{~m} / \mathrm{s}, Q=150 \mathrm{~L} / \mathrm{min}$

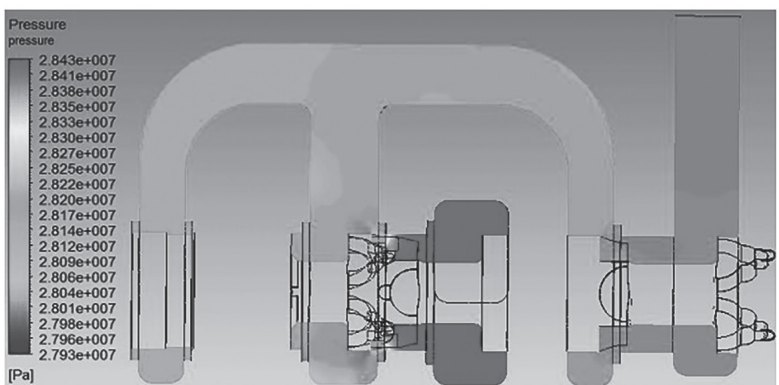

Simulation $2: L=4 \mathrm{~mm}, v=1.3 \mathrm{~m} / \mathrm{s}, Q=26.6 \mathrm{~L} / \mathrm{min}$

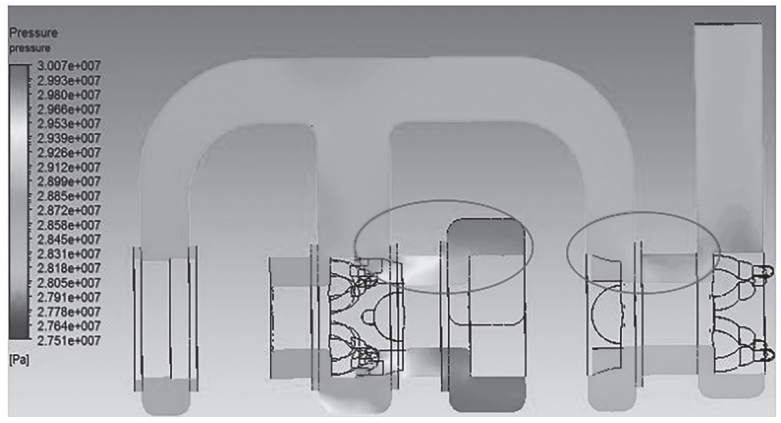

Simulation 4: $L=10 \mathrm{~mm}, v=16 \mathrm{~m} / \mathrm{s}, Q=350 \mathrm{~L} / \mathrm{min}$

Fig. 11. Pressure distributions for different orifice opening widths.

Table 6. Simulation scheme for the speed control performance of the crane hoisting system

\begin{tabular}{ccccc}
\hline Simulation & Working condition & Workload (kg) & $\begin{array}{c}\text { Engine speeds } \\
(\mathrm{r} / \mathrm{min})\end{array}$ & $\begin{array}{c}\text { Pilot pressure } \\
(\mathrm{MPa})\end{array}$ \\
\hline 1 & No load and idle speed & 0 & 800 & 02.0 \\
2 & No load and high speed & 0 & 1900 & 02.0 \\
3 & Heavy load and idle speed & 4500 & 800 & 02.0 \\
4 & Heavy load and high speed & 4500 & 1900 & 02.0 \\
\hline
\end{tabular}
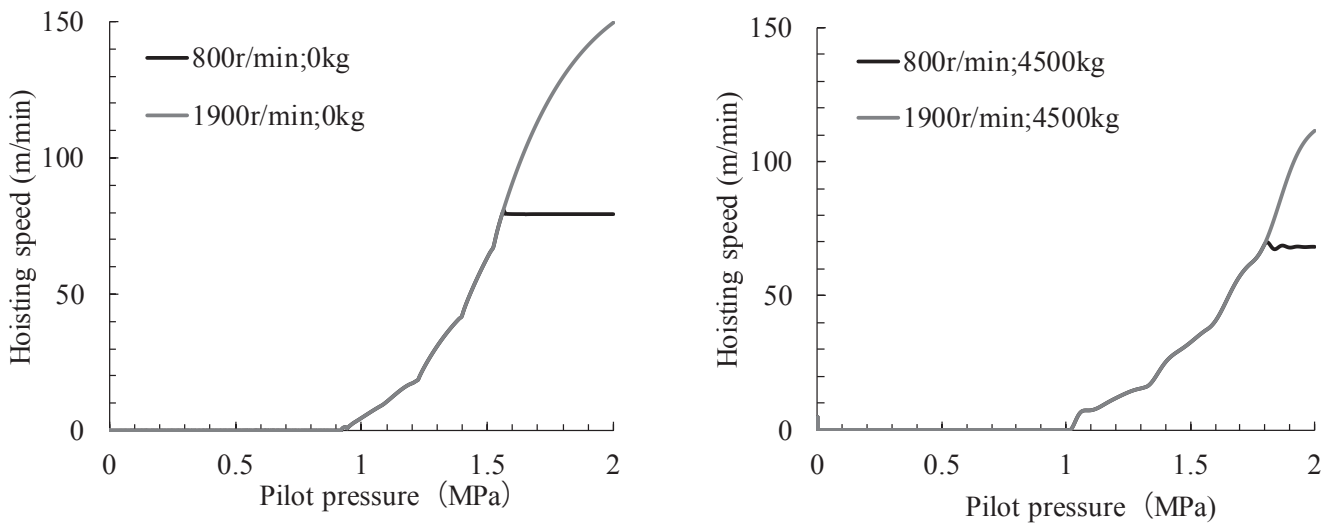

Fig. 12. Simulation results of the crane hoisting speed.

Figure 12 shows that the hoisting speed of the hoisting system increases with the pilot pressure. The pilot pressure of the orifice opening is respectively 0.9 and 1.1 $\mathrm{MPa}$ when the hoisting system is under no-load and heavy-load conditions. In simulation 1 , the hoisting system achieves a maximum hoisting speed of $80 \mathrm{~m} / \mathrm{min}$ when the pilot pressure reaches $1.56 \mathrm{MPa}$. In simulation 2 , the hoisting speed is a maximum of $150 \mathrm{~m} / \mathrm{min}$ when the pilot pressure reaches $2 \mathrm{MPa}$. In simulation 3 , the hoisting speed is a maximum of $70 \mathrm{~m} / \mathrm{min}$ when the pilot pressure reaches $1.8 \mathrm{MPa}$. In simulation 4 , the hoisting speed is a maximum of $110 \mathrm{~m} / \mathrm{min}$ when the pilot pressure reaches $2 \mathrm{MPa}$. The leakage of the hydraulic system increases in response to an increase in the workload. Therefore, for the same engine speed, the hoisting speed under a heavy load is lower than that under a light load. 
Performance test results and analysis of the crane hoisting system

Table 7 shows the test scheme adopted to analyze and verify the effect of the designed combined orifice on the hoisting speed under different working conditions of the crane hoisting system.

Figure 13 presents curves of the hoisting speed versus pilot pressure for different working conditions.

Figure 13 shows that the hoisting speed of the crane hoisting system varies steadily with the pilot pressure. The pilot pressure of the orifice opening is $1 \mathrm{MPa}$. In simulation 1, the hoisting speed is a maximum of $75 \mathrm{~m} /$ min when the pilot pressure reaches $1.64 \mathrm{MPa}$. In simulation 2, the hoisting speed is a maximum of $150 \mathrm{~m} / \mathrm{min}$ when the pilot pressure reaches $2 \mathrm{MPa}$. In simulation 3 , the hoisting speed is a maximum of $71 \mathrm{~m} / \mathrm{min}$ when the pilot pressure reaches $1.78 \mathrm{MPa}$. In simulation 4 , the hoisting speed is a maximum of $112 \mathrm{~m} / \mathrm{min}$ when the pilot pressure reaches $2 \mathrm{MPa}$.

Table 8 presents the test scheme adopted to measure the lowest stable hoisting speed when testing the low-speed performance of the hoisting system.

Table 7. Test scheme of the hoisting speed of the crane hoisting system

\begin{tabular}{ccccccc}
\hline Test & Working condition & $\begin{array}{c}\text { Angle of tilt } \\
\text { cylinder (deg) }\end{array}$ & $\begin{array}{c}\text { Length of telescopic } \\
\text { boom }(\mathrm{m})\end{array}$ & $\begin{array}{c}\text { Workload } \\
(\mathrm{kg})\end{array}$ & $\begin{array}{c}\text { Engine speeds } \\
(\mathrm{r} / \mathrm{min})\end{array}$ & $\begin{array}{c}\text { Pilot pressure } \\
(\mathrm{MPa})\end{array}$ \\
\hline 1 & No load and idle speed & 60 & 19.8 & 0 & 800 & $0-2.0$ \\
2 & No load and high speed & 60 & 19.8 & 0 & 1900 & $0-2.0$ \\
3 & Heavy load and idle speed & 60 & 19.8 & 4500 & 800 & $0-2.0$ \\
4 & Heavy load and high speed & 60 & 19.8 & 4500 & 1900 & $0-2.0$ \\
\hline
\end{tabular}

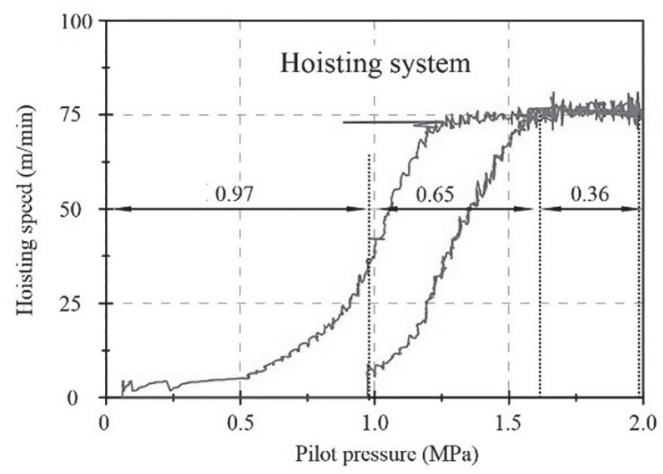

Test 1: No load and idle speed

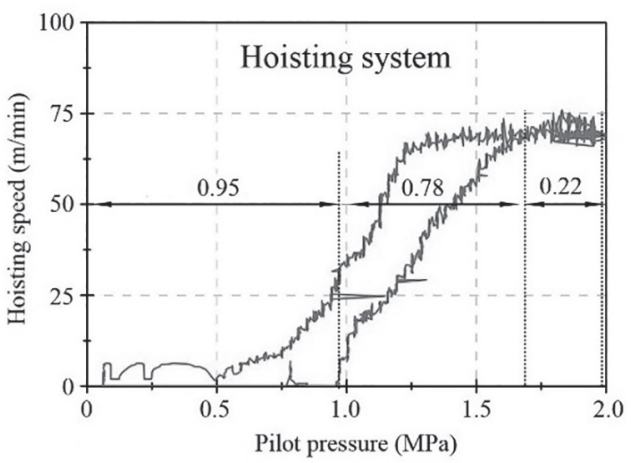

Test 3: Heavy load and idle speed

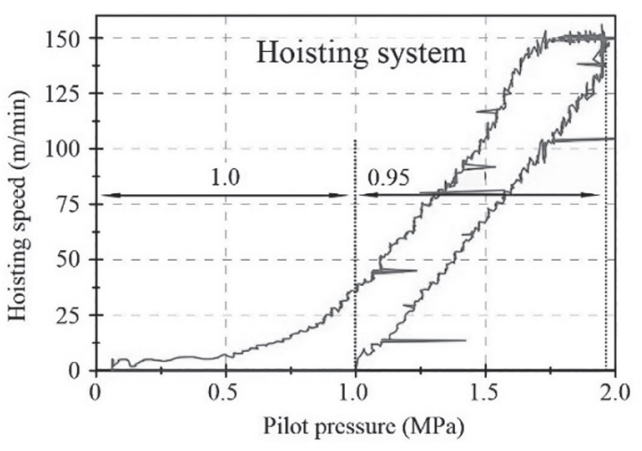

Test 2: No load and high speed

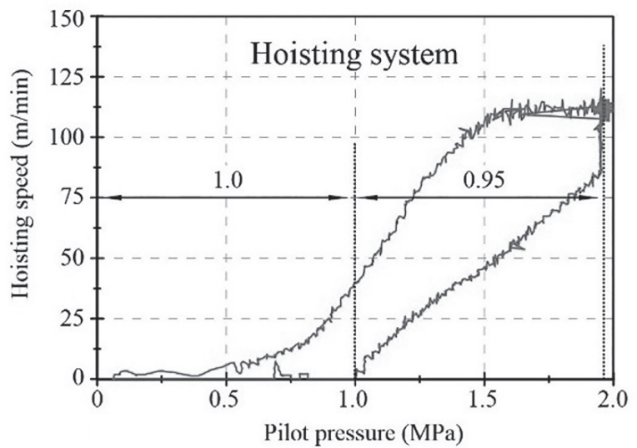

Test 4: Heavy load and high speed

Fig. 13. Hoisting speed versus pilot pressure.

Table 8. Test scheme for low-speed operation of the crane hoisting system

\begin{tabular}{cccccc}
\hline Test & Working condition & $\begin{array}{c}\text { Angle of tilt } \\
\text { cylinder }(\mathrm{deg})\end{array}$ & $\begin{array}{c}\text { Length of telescopic } \\
\text { boom }(\mathrm{m})\end{array}$ & $\begin{array}{c}\text { Workload } \\
(\mathrm{kg})\end{array}$ & $\begin{array}{c}\text { Engine speeds } \\
(\mathrm{r} / \mathrm{min})\end{array}$ \\
\hline 1 & No load and lifting & 60 & 11.6 & 0 & 800 \\
2 & No load and lowering & 60 & 11.6 & 0 & 800 \\
3 & Heavy load and lifting & 60 & 11.6 & 4500 & 800 \\
4 & Heavy load and lowering & 60 & 11.6 & 4500 & 800 \\
\hline
\end{tabular}




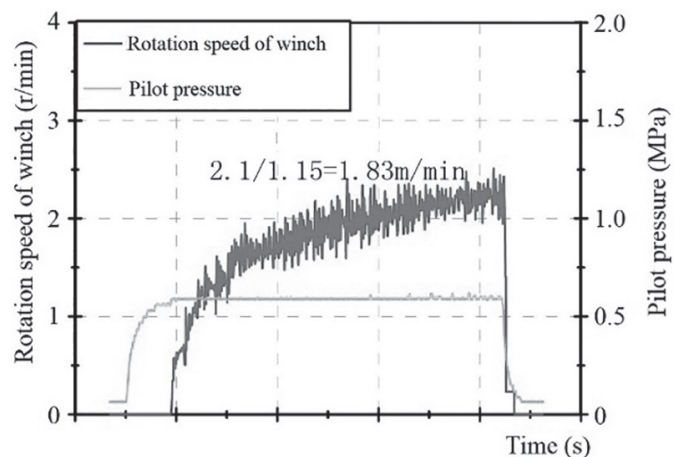

Test 1: No load and lifting

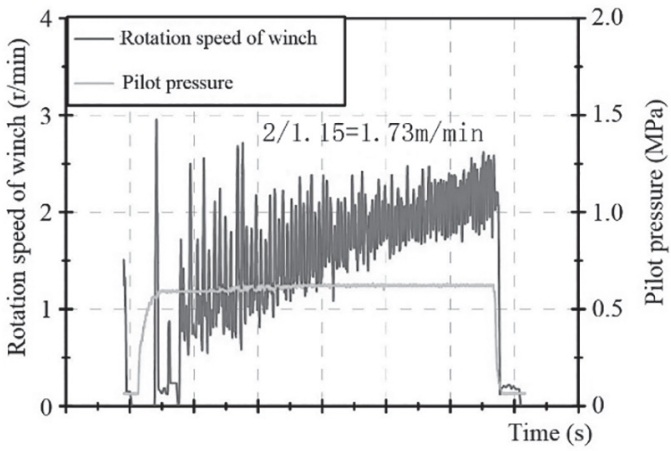

Test 3: Heavy load and lifting

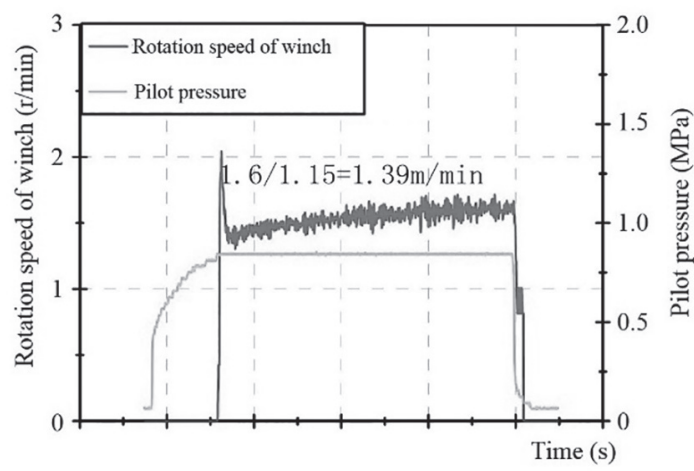

Test 2: No load and lowering

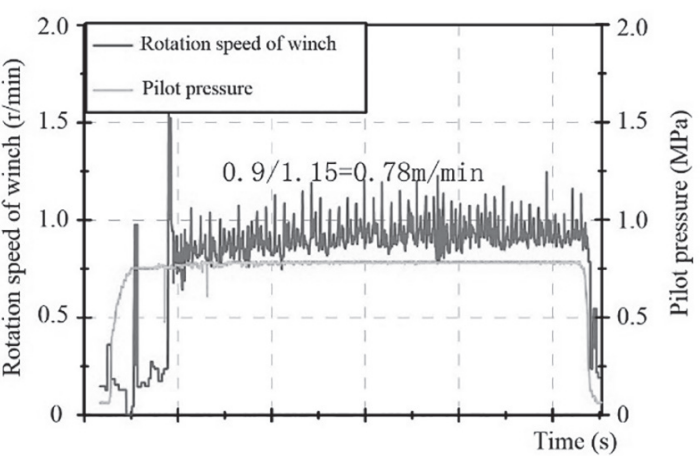

Test 4: Heavy load and lowering

Fig. 14. Lowest stable speeds of the crane hoisting system under different working conditions.

The hoisting system of the crane is controlled by manual operation of the hydraulic pilot control handle such that the system works at the lowest stable speed. The lowest stable speeds of the crane hoisting system under different working conditions are shown in Figure 14.

Figure 14 shows that the minimum stable speed of the hoisting system under different working conditions is less than $1.83 \mathrm{~m} / \mathrm{min}$. The hoisting system of the crane can operate stably at a lower speed when it is lowering under a heavy load.

\section{CONCLUSIONS}

The present study calculated the equivalent flow areas of four commonly used single orifices. Calculation results show that the flow area of the U-shaped throttle slot is small and stable at a small orifice opening width while the flow area gain is large at a large orifice opening width, which meets the requirements of stability of the crane hoisting system for low-speed motion and high efficiency for fast motion.

According to the hoisting speed requirements of the crane hoisting system, a combined orifice was designed with a U-shaped orifice and the flow area was calculated. Calculation results show that the maximum opening width of the combined throttle is $10 \mathrm{~mm}$. The total flow area is low (increasing from 0 to $60 \mathrm{~mm}^{2}$ ) for opening widths of $0-5.2 \mathrm{~mm}$ and increases rapidly from 60 to $213 \mathrm{~mm}^{2}$ for opening widths of $5.2-10 \mathrm{~mm}$

The CFD method was used to simulate the pressure distribution of the combined orifice at different opening widths. The simulation results show that the pressure loss at the orifice is less than $1.5 \mathrm{MPa}$. A simulation model of the crane hoisting system was established in AMESim software and the performance of hoisting speed regulation was analyzed. Results show that the hoisting speed of the hoisting system increases with the pilot pressure. When the hoisting system is under no-load and heavy-load conditions, the pilot pressure of the orifice opening is 0.9 and $1.1 \mathrm{MPa}$, respectively. When the system has no load and the engine is idling, the maximum hoisting speed is $80 \mathrm{~m} / \mathrm{min}$. When the system has no load and the engine is running at high speed, the maximum hoisting speed is $150 \mathrm{~m} / \mathrm{min}$. When the load of the system is high and the engine is idling, the maximum hoisting speed is $70 \mathrm{~m} / \mathrm{min}$. When the load of the system is high and the engine is running at high speed, the maximum hoisting speed is $110 \mathrm{~m} / \mathrm{min}$. An increase in workload increases the leakage of the hydraulic system. The maximum hoisting speed of the hoisting system under a heavy load is lower than that under a light load for the same engine speed.

Results of the speed regulation test of the crane hoisting system show that the maximum hoisting speed of the hoisting system is $75 \mathrm{~m} / \mathrm{min}$ when the system has no load and the engine is idling. The maximum hoisting speed of the hoisting system is $150 \mathrm{~m} / \mathrm{min}$ when the system has no load and the engine is running at high speed. The maximum hoisting speed of the hoisting system is $71 \mathrm{~m} / \mathrm{min}$ when the load of the system is high and the engine is idling. The maximum hoisting speed of the 
hoisting system is $112 \mathrm{~m} / \mathrm{min}$ when the load of the system is high and the engine is running at high speed. The minimum stable speed of the hoisting system is less than $1.83 \mathrm{~m} / \mathrm{min}$ under different working conditions. The hoisting system of the crane operates stably at low speed when it lowers a heavy load. The results of the speed regulation test of the crane hoisting system are basically the same as those of the simulation test, which demonstrates the correctness of the model.

\section{AUTHOR CONTRIBUTIONS}

M. S. Li designed the study, analyzed the data and wrote the paper. M. Mitsuoka and E. Inoue designed the study, supervised the work and provided facilities and resources. T. Okayasu, Y. Hirai participated in the design of the study and performed the simulation. X. X. Song edited the English text of a draft of this manuscript. All authors assisted in editing the manuscript and approved the final version.

\section{ACKNOWLEDGEMENTS}

The authors acknowledge financial support from the National Key Research and Development Program of China (No. 2016YFD0701001) and Chinese Scholarship Council.

\section{REFERENCES}

Na, C. L. 1993 Determination of the sectional area of triangle orifice channel. Journal of Gansu University of Technology, 19(6): $45-48$

Ji, H., Fu, X. and Yang, H. Y. 2003 Analysis and calculation on typical shape orifice areas in hydraulic valves. Machine Tool and Hydraulics, 31(5): 14-16

Ji, H., Zhang, J. H. and Wang, D. S. 2010 Flow coefficient of rectangular notch orifice in spool valve. Journal of Lanzhou University of Technology, $\mathbf{3 6}(3)$ : 47-50

Zhou, H., Deng, B. and Liu, H. L. 2008 Areas calculation and characteristics analysis on combined shape orifice in hydraulic valves. Mechanical Research and Application, 16(1): 80-85

Wu, X. M., Yao, J. Y. and Li, W. 2010 The numerical simulation of spool valve with $\mathrm{U}+\mathrm{K}$ notches. Fluid Power Transmission and Control, $\mathbf{4 2}(5)$ : 13-15

Dasgupta, K. and Karmakar, R. 2002 Modeling and dynamics of single-stage pressure relief valve with directional damping. Simulation Modeling Practice and Theory, 10(1/2): 51-67

Yuan, S. H., Yin, C. B. and Liu, S. H. 2013 Working Properties of Counterbalance Valve Based on AMESim Code. Transactions of the Chinese Society for Agricultural Machinery, 44(8): 273-280

Amirante, R., Moscatelli, P. G. and Catalano, L. A. 2007 Evaluation of the flow force on a direct (single stage) proportional valve by means of a computational fluid dynamic analysis. Energy Conversion and Management, 48(3): 942-953

Li, Z., Jing, L. and Yuan, R. B. 2012 The CFD analysis of twin flapper-nozzle valve in pure water hydraulic. Procedia Engineering, 31: 220-227 